\title{
GaN Based HEMT Power Amplifier Design with 44.5dBm Output Power Operating at 5-7GHz
}

\author{
Syed Mudassir Hussain ${ }^{1 a}$, Talha Mir ${ }^{1 b}$, Mehr Gul $^{2 a}$, Atiq Ur Rehman ${ }^{2 b}$, Zahid Rauf ${ }^{2 c}$
}

RECEIVED ON 22.10.2020, ACCEPTED ON 16.12.2020

\begin{abstract}
The next-generation wireless communication systems including satellite, radar, and mobile communications need application-specific power amplifiers that can operate at very high frequencies and high power with the overall minimum power consumption from the system. To meet such stringent requirements there is a rising interest in amplifier designs based on GaN transistors. This paper presents an improved design of a high power amplifier based on GaN HEMT transistor operating at the frequency band $5 \mathrm{GHz}-7 \mathrm{GHz}$ with optimized output power level. The presented design is based on a 12 Watt Discrete Power GaN on SiC HEMT from TriQuint. In this manuscript, we have considered the stability of the amplifier for the whole operating frequency band, its input and output matching impedance, gain, and maximum output power. The design of the Radio Frequency (RF) power amplifier and its overall performance are carried out using an advanced design system (ADS). The simulation results of the device stability and the output power level achieved provides a good comparison with the parameters and specifications of the device used. For better correlations in the simulation results and measurements, the accuracy of passive element designs are also considered. The simulation and experiment results show that the designed high power amplifier has achieved an output power level of $44.5 \mathrm{dBm}$ at $1 \mathrm{~dB}$ compression point.
\end{abstract}

Keywords: Power Amplifiers, Stability, Impedance Matching, High Electron Mobility Transistors.

\section{INTRODUCTION}

$\mathrm{P}$ ower amplifier is considered a key module for any mobile or wireless communication system [1]. Therefore, its stability at the operating frequency band, output power level, and the Power Added Efficiency (PAE) are always considered during its design. The performance of many semiconductor devices can provide a limitation over various operational frequencies thereby reducing the performance of the power amplifier required for the specific application. The technologists have developed high-performance materials to handle the high frequencies, output powers and variable thermal conditions $[3,10]$.

The materials with large breakdown regions like GaN High Electron Mobility Transistors (HEMTs) are proven to be very useful to meet the requirements of wideband mobile applications. Moreover, other devices like SiC MESFET and Gallium Arsenide have also provided developments in the design of highly efficient power amplifiers [1 - 4]. GaN-based transistors can provide better performance as compared to the conventional materials and hence are of great interest to the Researchers in the

${ }^{1}$ Department of Electronic Engineering, Faculty of Information and Communication Technology, Balochistan University of Information Technology, Engineering and Management Sciences, Quetta, Balochistan, Pakistan. Email: ${ }^{a}$ mudassir.hussain@ @uitms.edu.pk, (Corresponding author), ${ }^{\text {b talha.mir@ @ buitms.edu.pk }}$

2 Department of Electrical Engineering, Faculty of Information and Communication Technology, Balochistan University of Information Technology Engineering and Management Sciences, Quetta, Balochistan, Pakistan.

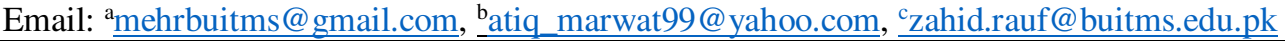

This is an open access article published by Mehran University of Engineering and Technology, Jamshoro under CC BY 4.0 International License. 
communication domain.

GaN-based materials can tolerate high power density. This property not only allows the development of micro devices with similar output power performance but also provide higher impedances as well. The availability of higher impedance makes it easier for the circuit designer to match the impedance of the system which reduces extra cost requirements and the complexity such as required by the conventional materials like GaAs. Furthermore, the property of high voltage can greatly reduce the requirement of voltage conversion which may lead to high power-added efficiency. Hence the overall cost of the system design will also be reduced.

\section{RELATED WORK}

The careful design of the power amplifier make it capable and efficient for operating in wideband applications at higher frequency. The optimized power efficiency and output power levels can improve the amplifier's performance that will lead to improving the system's efficiency with the limited power conditions especially for those operating in the aircraft and space environments. Moreover, this wide band operation can also be very useful for future $4 \mathrm{G} / 5 \mathrm{G}$ mobile communication systems. Due to the promising electrical properties of GaN HEMT power amplifiers, it is considered to be an appropriate choice of use for high thermal conditions and high operating voltages [5].

The mobile communication systems and radar systems need an output power level higher than 20W [8]. The performance of $\mathrm{GaN}$ is far superior to the GaAs both in terms of output power and power-added efficiency operating at the frequency bandwidth $1 \mathrm{GHz}$ to $12 \mathrm{GHz}$. $\mathrm{AlGaN} / \mathrm{GaN}$ technology-based power amplifier biased at $20 \mathrm{~V}$ for the $\mathrm{X}$ band application provided an output power between $21 \mathrm{~W}$ to $28.5 \mathrm{~W}$ for the frequency range from $8-10.5 \mathrm{GHz}$. The peak performance of this amplifier design provided an output power of $30 \mathrm{~W}$ for the frequency ranging $8.5-9 \mathrm{GHz}[6,9]$. A $10 \mathrm{~W}$ power amplifier achieved an output power level of $42.03 \mathrm{dBm}$ at $2.4 \mathrm{GHz}$ [9]. In one application of a $\mathrm{GaN}$ based amplifier also achieved a highly efficient and stable design which attained $35 \mathrm{dBm}$ output power with a wide band of 30 to $500 \mathrm{MHz}$ [11]. In another work, GaN material based amplifier achieved an output power level of $20 \mathrm{~W}$ for radio frequency applications [7]. In another work supported by the European Defense agency GaN HEMT amplifier achieved an output power level of $46 \mathrm{dBm}$ at the drain bias voltage of $25 \mathrm{~V}$. Further, at $9 \mathrm{GHz}$ when the bias voltage was increased to $32 \mathrm{~V}$ the achieved output power reached the level of $47.7 \mathrm{dBm}$. The large-signal model design of the power amplifier presented in $[12,13]$ achieved an output power of $41.43 \mathrm{dBm}$ while operating at the frequency range of $1-3 \mathrm{GHz}$. The drain bias voltage was set to $28 \mathrm{~V}$. Using the GaN-based power devices and by setting the drain bias voltage to an appropriate level the optimized output power levels can be achieved with better power-added efficiency.

\section{METHODOLOGY}

The major steps considered for designing a power amplifier on a 12 Watt Discrete Power GaN on SiC HEMT from TriQuint to achieve an optimized output power include. (1) Calculating the stability of the amplifier at the given frequency band, (2) Impedance matching network design, (3) Power amplifier characterization, and (4) Design optimization.

\subsection{Stability Factor}

The circuit shown in Fig. 1 is designed to obtain the bias point for the amplifier, the DC IV characteristics of the device are obtained as a drain to source voltage $\left(\mathrm{V}_{\mathrm{DS}}\right)$ from $0 \mathrm{~V}$ to $50 \mathrm{~V}$ is varied and the corresponding drain to source current $\left(\mathrm{I}_{\mathrm{DS}}\right)$ values are obtained respectively.

\subsection{Biasing Network design}

Drain and gate biasing networks are designed using a microstrip substrate [14], where the physical and substrate parameters are measured in LineCal, the center frequency was set at $6 \mathrm{GHz}$. The measured values of the biasing networks are summarized in Table 1.

\subsection{Stability vs Frequency}

The next step of the amplifier design is to evaluate the 


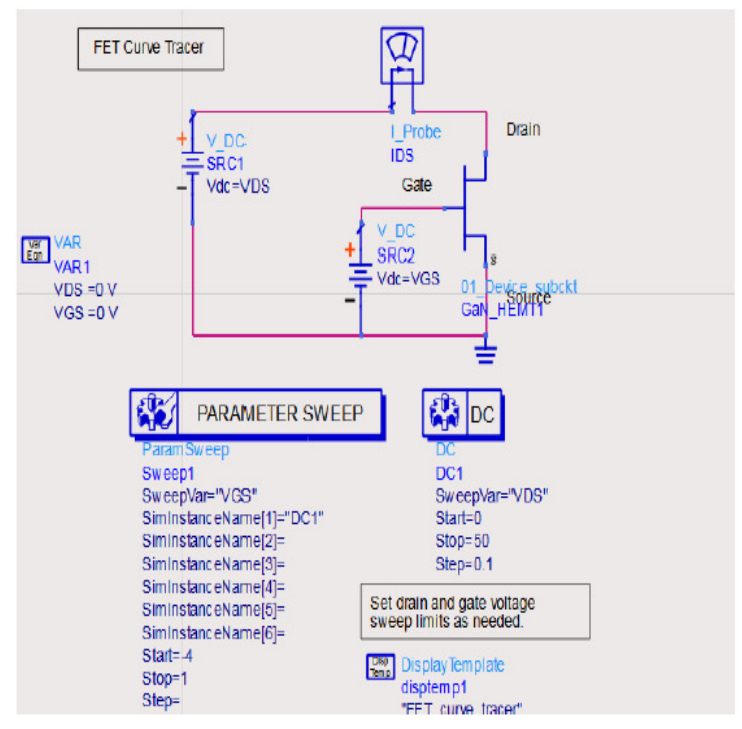

Fig. 1: Selected GaN HEMT IV Curve Setup

\begin{tabular}{|c|c|c|c|}
\hline \multicolumn{3}{|c|}{ Table 1: Biasing Networks Simulation Results } \\
\hline $\begin{array}{c}\text { Biasing } \\
\text { Network }\end{array}$ & $S_{11}$ & $S_{21}$ & Bandwidth \\
\hline $\begin{array}{c}\text { Drain } \\
\text { Biasing }\end{array}$ & $<-40 \mathrm{~dB}$ & $-0.04 \mathrm{~dB}$ & $\begin{array}{c}(5 \mathrm{GHz}- \\
7 \mathrm{GHz})\end{array}$ \\
\hline
\end{tabular}

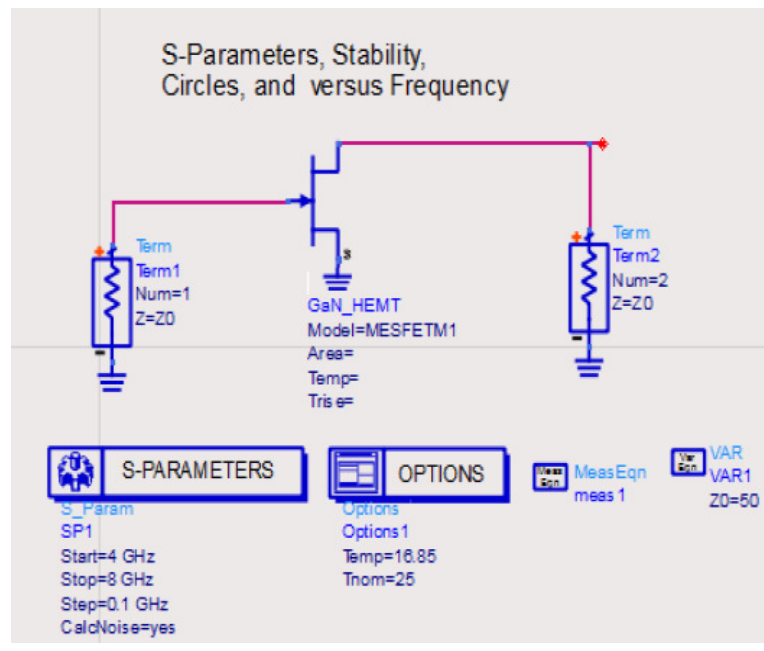

Fig.2: Circuit diagram for stability and maximum gain matching

stability of the device with the frequency for maximum gain and maximum gain matching impedances (Fig. 2) for the load and source [16]. The $\mathrm{RF}$ frequency selector is set to $6 \mathrm{GHz}$ and then the $\mathrm{S}$ parameters, stability factors, maximum available gain, and stability circles are calculated through simulation. The stability of the amplifier is very essential and the amplifier must be stable for the whole operating frequency band otherwise the amplifier will be an oscillating circuit $[17,18,19,20]$. The scattering parameters are calculated to evaluate the stability, it can be calculated by the following equation [15].

$\mathrm{K}=\frac{1-\left|\mathrm{S}_{11}\right|-\left|\mathrm{S}_{22}\right|+\left|\mathrm{S}_{11} \cdot \mathrm{S}_{22}-\mathrm{S}_{12} \cdot \mathrm{S}_{21}\right|^{2}}{2 \cdot\left|\mathrm{S}_{11}\right| \cdot\left|\mathrm{S}_{22}\right|}>1$

It can be seen that $K>1$ in equation (1). These parameters can be calculated using the Advanced Design System (ADS) [13]. In Fig. 3 stability factor $\mathrm{K}$, and the Geometric stability factors $\mu \_$source and $\mu \_$load are found to be greater than 1 showing the amplifier is unconditionally stable from $5 \mathrm{GHz}-7 \mathrm{GHz}$. If either mu_source or mu_load is $\mathrm{K}>1$, the circuit is unconditionally stable.

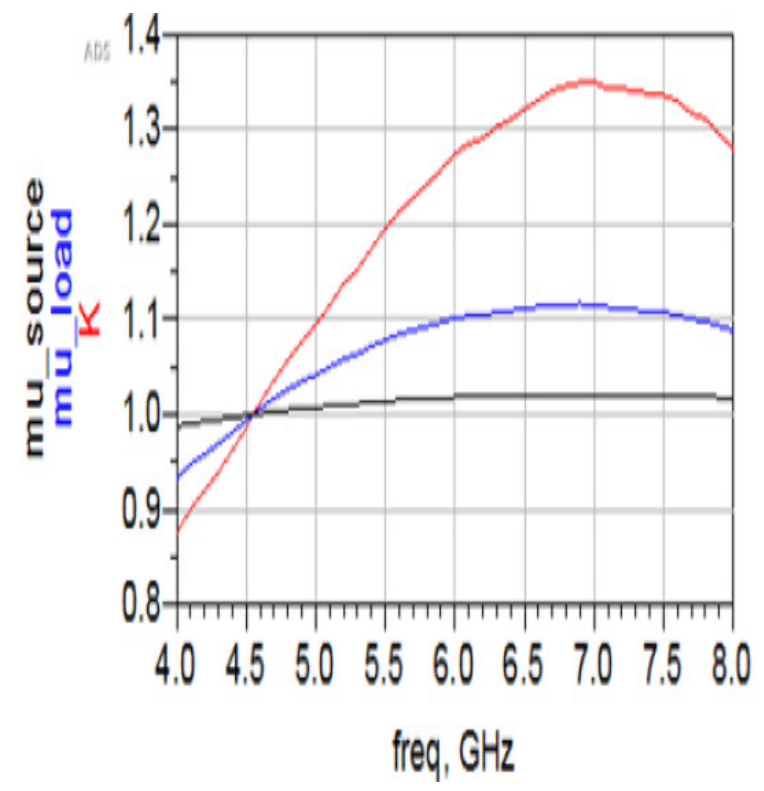

Fig. 3: $\mu \_$source and $\mu \_$load stability graph

\section{SIMULATION RESULTS}

Design and simulations of the power amplifier are carried out using the ADS. The simulation results of the device stability and the output power level achieved provides a good comparison with the parameters and specifications of the devices used. Fig.4 shows the maximum available gain, associated power gain, and $\mathrm{dB}(\mathrm{S} 21)$ when input and output networks are matched. 


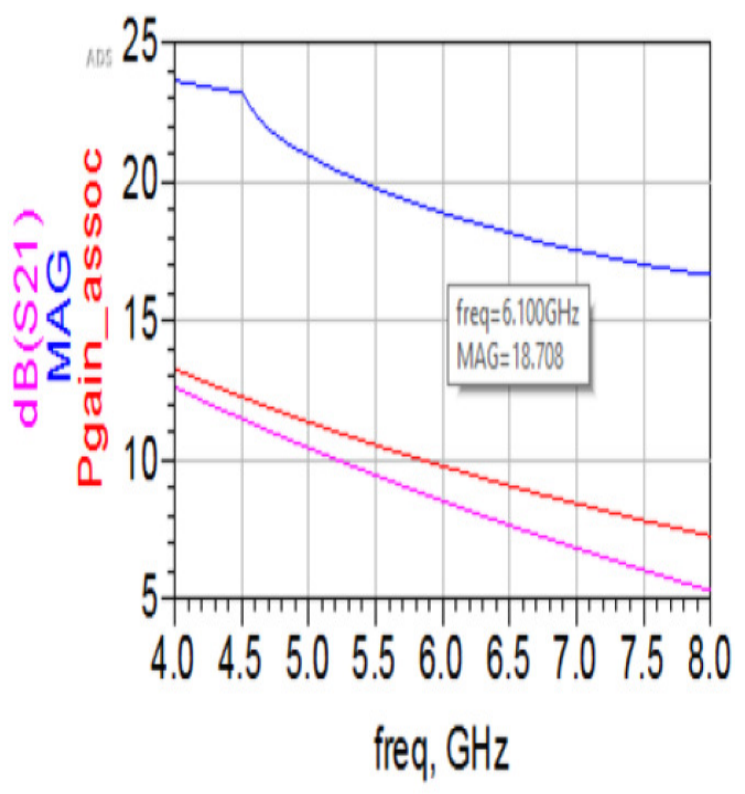

Fig. 4: Magnitude of Maximum available gain at $6 \mathrm{GHz}$

Fig. 5 shows the forward transmission $\left(\mathrm{S}_{21}\right)$ forward transmission is a signal at port 2 for an input signal for port 1 , and the reverse transmission signals showing $\mathrm{S}_{12}=7 \mathrm{~dB}$ for the $5 \mathrm{GHz}$ to $7 \mathrm{GHz}$ and $\mathrm{S}_{12}$ reverse transmission of $-35 \mathrm{~dB}$, Fig. 6 shows the constant voltage wave ratio.

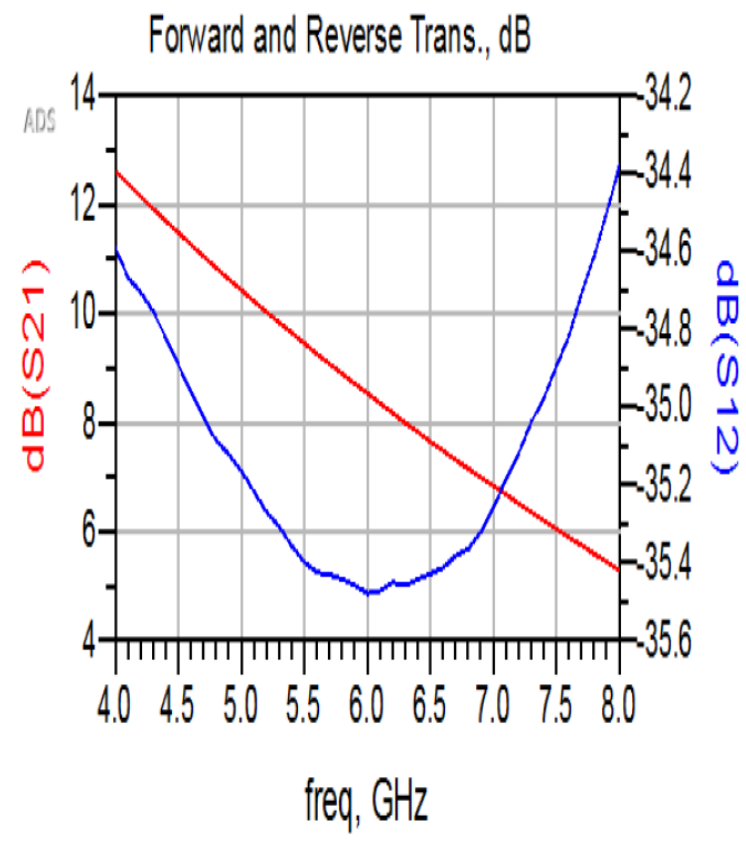

Fig.5: Forward and Reverse Transmission

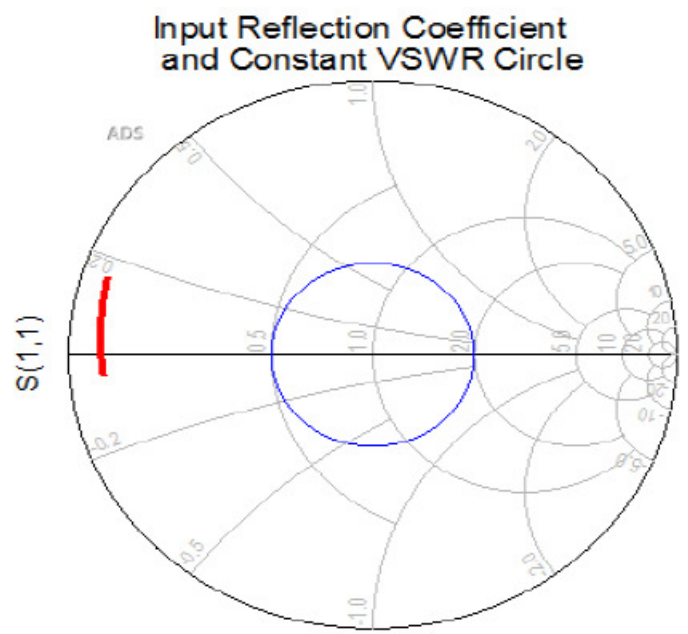

Fig. 6: Voltage Standing Wave ratio Circle (VSWR)

Fig. 7 shows the final design and layout of our amplifier combining the biasing networks and impedance matched input and output matching network.

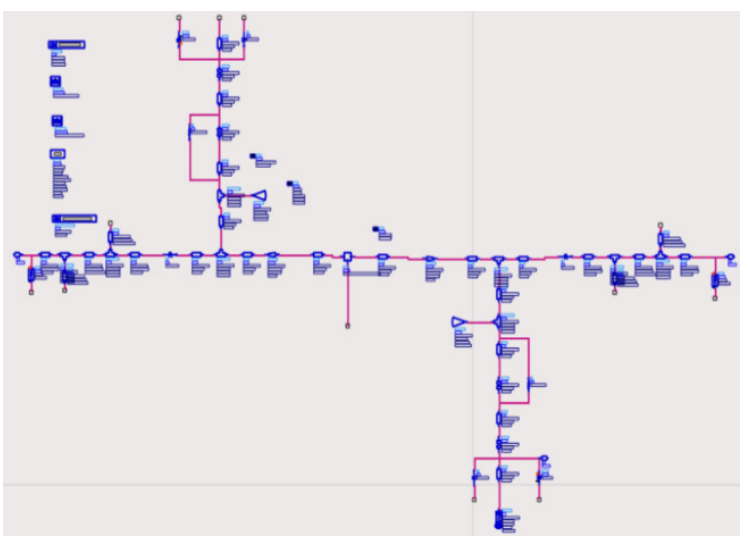

Final microwave Power Amplifier circuit

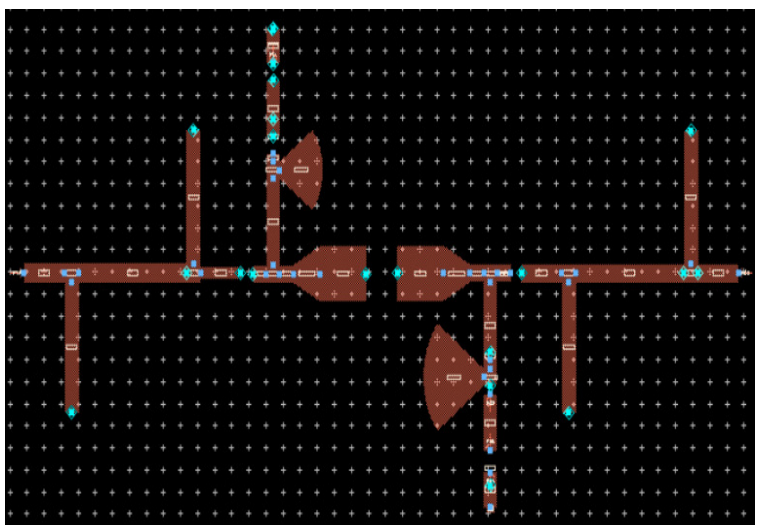

Fig. 7: Final microwave Power Amplifier circuit Layout 


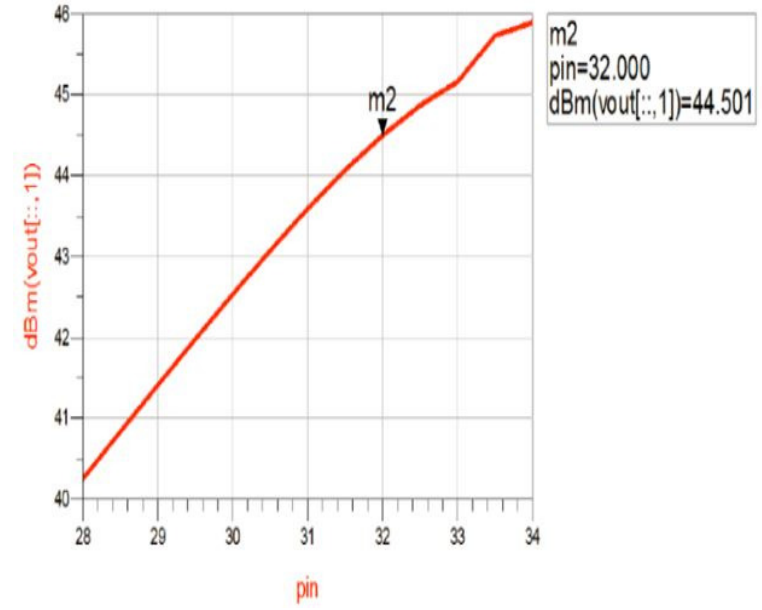

Fig. 8: Output Power Achieved

Fig. 8 shows the total output power achieved at the available bandwidth $(5-7 \mathrm{GHz})$ at the center frequency $6 \mathrm{GHz}$, an output power of $44.5 \mathrm{dBm}$ is obtained for the given input power of $32 \mathrm{dBm}$. For each frequency component, the corresponding input power is variable, because the driver circuit for the setup cannot provide similar power for the whole band of interest.

\begin{tabular}{|c|c|c|}
\hline \multicolumn{3}{|c|}{ Table 2: Summary of Results } \\
\hline Objectives & $\begin{array}{l}\text { Results of this } \\
\text { work }\end{array}$ & $\begin{array}{c}\text { Results of } \\
\text { Work done } \\
{[13]}\end{array}$ \\
\hline Device & $\begin{array}{c}12 \mathrm{~W} \text { GaN- } \\
\text { Based HEMT } \\
\text { on SiC from } \\
\text { TriQuint } \\
\text { (TGF2023-2- } \\
\text { 02) } \\
\end{array}$ & $\begin{array}{c}10 \mathrm{~W} \text { GaN } \\
\text { power } \\
\text { amplifier } \\
\text { from Cree } \\
(\mathrm{CGH} 40010 \mathrm{~F})\end{array}$ \\
\hline Bandwidth & $\begin{array}{c}5 \mathrm{GHz}-7 \mathrm{GHz} \\
\text { center } \\
\text { frequency } \\
6 \mathrm{GHz}\end{array}$ & $\begin{array}{c}1 \mathrm{GHz}-3 \mathrm{GHz} \\
\text { center } \\
\text { frequency } \\
2 \mathrm{GHz}\end{array}$ \\
\hline Amplifier type & Class AB & Class AB \\
\hline Operation & $28 \mathrm{~V}-32 \mathrm{~V}$ & $28 \mathrm{~V}$ \\
\hline $\begin{array}{c}\text { Output power } \\
\text { Achieved }\end{array}$ & $44.5 \mathrm{dBm}$ & $41.43 \mathrm{dBm}$ \\
\hline Stability & $\begin{array}{c}\text { Stable for the } \\
\text { whole band }\end{array}$ & $\begin{array}{c}\text { Stable for the } \\
\text { whole band }\end{array}$ \\
\hline
\end{tabular}

In this design we chose the RF frequency range of 5$7 \mathrm{GHz}$ with the center frequency of $6 \mathrm{GHz}$ and calculated the output power of $44.5 \mathrm{dBm}$. The results obtained are compared with the already work done on 10W GaN-based power amplifiers. A comparison of results is given in Table 2 in terms of operating frequency and the output power levels.

\section{CONCLUSIONS}

Power amplifiers are considered to be a vital part of any modern communication systems. GaN-based HEMT power amplifier design can provide better output power levels to meet the high operating voltages requirements. This paper presents an improved design of a high power amplifier based on GaN HEMT transistor operating at the frequency band $5 \mathrm{GHz}-7 \mathrm{GHz}$ with optimized output power level. The presented design is based on a 12 Watt discrete power GaN on SiC HEMT from TriQuint. In this manuscript, we have considered the stability of the amplifier for the whole operating frequency band, its input and output matching impedance, gain, and maximum output power. The design of the RF power amplifier and its overall performance are carried out using the ADS. The simulation and experiment results show that the designed high power amplifier has achieved an output power level of $44.5 \mathrm{dBm}$ at $1 \mathrm{~dB}$ compression point.

\section{ACKNOWLEDGMENT}

The authors would like to thank the anonymous reviewers for their precious comments to improve the manuscript. This work is supported by the Department of Electronic Engineering, FICT, BUITEMS, Quetta, Pakistan.

\section{REFERENCES}

1. Mishra U.K., Parikh P., Wu Y.F., "AlGaN/GaN HEMTs An overview of device Operation and applications", Proceedings of the IEEE, Vol. 90, No. 6, pp. 1022-1031, 2002.

2. GaN overview. [Online]. http: //www.gainmicrowave.com/gallium_nitride_ove rview.php. [Last accessed 2019].

3. Saunier P., "GaN Technology Overview: Accomplishments and challenges", Proceedings of the Gallium Arsenide Applications Symposium (GAAS), 11-12 Ottobre, Amterdam, 2004.

4. Hsu S.S.H., Pavlidis D., "Low noise AlGaN/GaN 
MODFETs with high breakdown and power characteristics", Proceedings of the IEEE Gallium Arsenide Integrated Circuit Symposium. 23rd Annual Technical Digest, pp. 229-232, Baltimore M.D., 21-24 October 2001.

5. Seo S., "GaN-based Heterostructure Field-Effect Transistors and MMICs for High Frequency Applications," PhD Thesis, Technical University of Darmstadt, Darmstadt, 2008.

6. Huet T., Gruenenpuett J., Ouarch Z., Bouw D., Serru V., Camiade M., Chang C., Chaumas P. "A $8 \mathrm{~W}$ high efficiency $\mathrm{X}$-band power pHEMT amplifier", Proceedings of the 38th European Microwave Conference, pp.289 -292, Amsterdam, Netherlands, 27-31 October 2008.

7. Chu C.-K., Huang H.-K., Liu H.-Z., Lin C.-H., Chang C.-H., Wu C.-L., Chang C.-S., Wang Y.H. "An X-band high-power and high-PAE PHEMT MMIC power amplifier for pulse and CW operation", IEEE Microwave and Wireless Components Letters, Vol. 18, No. 10, pp.707 -709 2008.

8. Kuhn J., "AlGaN/GaN-HEMT Power Amplifiers with Optimized Power-Added Efficiency for XBand Applications", PhD Dissertation, Karlsruher Institut für Technologie Fakultät für Elektrotechnik und Informationstechnik, 2010.

9. Ramya K., Shanthi P., "Design of Class-AB Power Amplifier using GaN HEMT Technology", Proceedings of the 4th International Conference for Convergence in Technology (I2CT), pp. 1-3, Mangalore, India, 2018.

10. Elshafiey, A. Fattah Sheta, M. Alam Nizam Uddin, W. M. Abdulkawi, Waqar A. Malik, "Adaptive Energy Concentration in Hyperthermia Treatment of Cancer", Proceedings of the IEEE Asia-Pacific Conference on Applied Electromagnetics (APACE), pp. 1-5, Melacca, Malaysia, 25-27 November 2019.

11. Kim J., Kim Y., Oh S., Choi J., Lee D.-H., Cho K., Lee S., Ahn C.-H., , "A 20-W Wide Bandwidth GaN HEMT Power Amplifier for VHF/UHF Applications", IEEE Transactions on Industrial Electronics, Vol. 67, No. 12, pp. 10905-10910, 2020.

12. Costrini C., Calori A., Lanzieri C., Lavanga S., Peroni M., Limiti E., Serino A., G C. Costrini.
Ghione, and G. Melone, “A 20 Watt Microstrip X-Band AlGaN/GaN HPA MMIC for Advanced Radar Applications," Proceedings of the 3rd European Microwave Integrated Circuits Conference (EuMIC), Amsterdam, Netherlands, pp. $566-569,2008$.

13. Yilmaz M. H., "Design of a wide band $10 \mathrm{~W} \mathrm{GaN}$ Power amplifier", Master Dissertation, Norwegian University of Science and Technology (NTNU), 2011.

14. Joshi R. K., Harish A. R., "Characteristics of a rotated butterfly stub", Proceedings of the IEEE MIT-S International Microwave Symposium, San Francisco, USA, 11-16 June 2006.

15. Luo X., Vue C., Zhou L., Yu W., Lv X., "Design of a Ka-band GaN HEMT Power Amplifier Based on Simulation", Proceedings of the International Workshop on Microwave and Millimeter Wave Circuits and System Technology, Chengdu, China, 24-25 October 2013.

16. Agilent Technologies. Guide to Harmonic Balance Simulation in ADS. Advanced Design System Product Documentation. February 2011.

17. Jeong H.- C., Oh H.- S.,, Ahmed, A.R., Yeom K.W., "Design of X-band $40 \mathrm{~W}$ Pulse-Driven GaN HEMT power amplifier", Asia Pacific Microwave Conference Proceedings (APMC), pp. 466 - 468, Kaohsiung, Taiwan, 4 - 7 December 2012.

18. Piotrowicz S., Morvan E., Aubry R., Bansropun S., Bouvet T., Chartier E., Dean T., Drisse O., Dua C., Floriot D., di-Forte Poisson M., Gourdel Y., Hydesa A., Jacquet J., Jardel O., Lancereau D., Lean J. M., Lecoustre G., Martin A., Ouarch Z., Reveyrand T., Richard M., Sarazin N., Thenot D., Delage S., "State of the Art 58W, 38\% PAE XBand AlGaN/GaN HEMTs Microstrip MMIC Amplifiers", Proceedings of the IEEE Compound Semiconductor Integrated Circuit Symposium, pp. 1 -4, Monterey, C.A., U.S.A., 12-15 October, 2008.

19. Bowick C.. "RF Circuit Design", Newnes Inc., 2008.

20. Cripps S. C., "RF Power Amplifiers for Wireless Communications", Artech House Inc., 2006. 